\title{
A theoretical and empirical examination of the transactional and non-leadership dimensions of the Multifactor Leadership Questionnaire (MLQ)
}

\author{
Timothy R. Hinkin \\ Cornell University \\ Chester A. Schriesheim
University of Miami
}

\begin{abstract}
Bass and his colleagues initiated the empirical investigation of transformational and transactional leadership two decades ago. They proposed that transformational leadership is comprised of four dimensions, that transactional leadership is composed of three dimensions, and that an additional category of non-leadership exists (laissez-faire leadership). The Multifactor Leadership Questionnaire (MLQ) has been developed to assess these dimensions and much has been learned about the positive effects of transformational leadership. However, far less attention has been paid to transactional leadership and non-leadership. The current study examined the theoretical and empirical properties of each MLQ transactional leadership and non-leadership measure. We first looked at the four measures together, then examined the measures separately and subjected them to a number of additional analyses that varied depending on the issues of concern. Based on our findings, we offer recommendations about scale refinement and the need for new theory concerning the four transactional leadership and non-leadership dimensions of the MLQ.
\end{abstract}

\section{Introduction}

The concepts of transformational and transactional leadership were first given in-depth treatment by Burns over 25 years ago (1978). Subsequently, Bass and his colleagues built on Bass's (1985) earlier work and proposed that transformational leadership is comprised of idealized influence (II), individualized consideration (IC), intellectual stimulation (IS), and inspirational motivation (IM), while transactional leadership is comprised of contingent reward (CRW), active management by exception (MBEA), and passive management by exception (MBEP). Additionally, a laissez-faire (LF) leadership dimension was conceptualized as essentially the absence of leadership.

Since the development of these constructs, the study of transformational leadership has continued and has, in fact, increased substantially in recent years (Dumdum, Lowe, \& Avolio, 2002). The vast majority of published empirical research on the topic has utilized the Multifactor Leadership Questionnaire (MLQ) developed by Bass and his associates (Bass, 1990; Bass \& Avolio, 1990, 1994; Seltzer \& Bass, 1990). Much has been learned about the positive effects of transformational leadership but far less attention has been paid to transactional leadership or non-leadership (laissez-faire leadership).

Bass and his colleagues have argued that transactional leadership is a necessary precondition for transformational leadership to be effective as it serves to develop the relationship between the leader and follower (Avolio, 1999). It also provides direction and focus that, if lacking, would result in confusion and ambiguity from the use of transformational behaviors. Contingent reward is the timely positive response to desired performance. Active management by exception is operationalized in terms of looking for mistakes, while passive management by exception is intervention only after problems become 
serious. While contingent reward has been the most studied sub-dimension of the MLQ, we know much less about the effects of management by exception and laissez-faire leadership. Recently, there have been studies that have looked at "non-leadership" or "passive leadership," which is typically measured by combining the MBEP and LF scales of the MLQ(e.g., Bass, Avolio, Jung, \& Berson, 2003; Den Hartog, Van Muijen, \& Koopman, 1997).

Those studies that have included the transactional and non-leadership measures have focused primarily on the factor structure of the MLQ, rather than on their relationships with outcome variables. Additionally, no attention has been given to a rigorous independent assessment of the theoretical content validity of these measures. However, in a review of the MLQ, Yukl (1999) was quite critical of the transactional leadership measures, and stated that "transactional leadership includes a diverse collection of (mostly ineffective) leader behaviors that lack any clear common denominator" (p. 289). Early versions of the MLQ did not differentiate between management by exception active and management by exception passive, but the most recent version (MLQ 5X-Rater; Bass \& Avolio, 1993) includes seven MBEP and MBEA items (each) and eight LF items.

The purpose of the current study is to examine the theoretical and empirical properties of each of the MLQ transactional and non-leadership measures. The study was conducted in four stages, each using analyses appropriate to examine issues and concerns raised about the measures under examination. In the first stage, we examine the four MLQ measures together. In stage 2, we then focus on the contingent reward scale. We next look at the active management by exception measure in stage 3. Finally, in stage 4, we use a second sample to further examine passive management by exception and laissez-faire leadership. To summarize, in our examination we are attempting to answer the following research questions:

1. Does a four-factor structure best represent the MLQTransactional Leadership measures?

2. Is the MLQ contingent reward measure multidimensional, as suggested by others?

3. Does the MLQ Active Management by Exception measure demonstrate sound psychometric properties?

4. Are the MLQ Passive Management by Exception and Laissez-Faire measures conceptually and empirically independent?

\author{
Methodology \\ Sample, procedure, and measures \\ Sample
}

The first sample was 237 line and supervisory employees working for two U.S. hotel companies at nine locations in the U.S. There were 42 referent managers, resulting in an average of 5.6 responses per manager. This variance in companies, locations, and managers can help to ameliorate potential context effects that may occur from using respondents from a single company and a single site. The average respondent age was 38 and $53 \%$ were male.

\title{
Procedure
}

Respondents were asked to rate the extent to which the manager to whom they directly reported exhibited each of the leadership behaviors included on our survey questionnaire. Also included were measures of satisfaction with the supervisor and supervisor effectiveness. The respondents were encouraged to answer all questions honestly, participation was voluntary, and the sample was assured of 
complete anonymity. Surveys were administered at the various properties and returned in person or by mail directly to the researchers.

\section{Measures}

The leader behavior measures consisted of the MLQ transactional and laissez-faire leadership scales (version MLQ-5X; Bass \& Avolio, 1993), and contingent reward (CR, 4 items) and contingent punishment (CP, 4 items) measures from the Leader Reward and Punishment Questionnaire (LRPQ; Podsakoff, Todor, Grover, \& Huber, 1984; Podsakoff, Todor, \& Skov, 1982). The LRPQhas demonstrated excellent psychometric properties in prior studies. The MBEA and MBEP scales each consist of seven items, while LF is made up of eight items and CRW has nine items. Satisfaction was measured using the five-item (each) supervisor-human relations and supervisor-technical ability subscales of the Minnesota Satisfaction Questionnaire (MSQ; Weiss, Dawis, England, \& Lofquist, 1967). This measure was used because of its good psychometric properties and because it assesses satisfaction with the supervisor rather than global satisfaction. The ten items were combined to create an overall satisfaction with supervision measure. Effectiveness was measured on six dimensions including technical competence, interpersonal skill, procedural justice, organizational influence, communication, and goal clarification. Respondents were asked to rate each of these dimensions on a seven-point scale from highly ineffective to highly effective. The six items were then aggregated to create a total effectiveness measure. Subordinate-rated satisfaction with supervision and supervisor effectiveness have been the most commonly used outcome variables in studies using the MLQ(Dumdum et al., 2002), so we were able to compare our findings to those of previous studies by using these variables. Coefficient alpha internal consistency reliabilities were computed for the measures. Except for MBEA (with alpha=.69), all the scales had acceptable reliabilities in excess of .70 (Nunnally \& Bernstein, 1994). The reliability results for MBEA are not atypical (e.g., Bass et al., 2003; Tejeda, Scandura, \& Pillai, 2001), and we will further discuss these results in our stage 3 investigation that is presented below.

\section{Stage 1: Examination of the transactional and laissez-faire leadership scales together}

The MLQ has been shown to have a relatively stable factor structure using confirmatory factor analysis in several previous studies (Antonakis, Avolio, \& Sivasubramaniam, 2003; Avolio, Bass, \& Jung, 1999). However, this has not always been the case and there have been several attempts at either modifying the measures or taking a subset of items that seem to demonstrate better psychometric properties (e.g., Den Hartog et al., 1997; Tejeda et al., 2001; Tepper \& Percy, 1994).

To examine the consistency of the current study data with prior research findings we subjected the four measures to confirmatory factor analyses (CFA) and computed correlations among the variables. Prior studies that have examined the transactional and laissez- faire items together using confirmatory factor analysis have typically found that the factor structure results in CRW and MBEA loading on independent factors while MBEP and LF sometimes load together on a single factor (Antonakis et al., 2003; Avolio et al., 1999; Den Hartog et al., 1997). The correlations between MBEP and LF have often exceeded.70, while the correlations between MBEA and MBEP typically range from .20 to .50 . CRW most commonly has a small negative relationship with MBEP and LF and a small positive relationship with MBEA (Tejeda et al., 2001).

\section{Analyses and results}

Based on theoretical expectations, using LISREL version 8.53 (Joreskog \& Sorbom, 2002), we employed item covariances and specified a (correlated) four-factor model to reflect each of the transactional and laissez-faire leadership constructs (using the $31 \mathrm{MLQ}$ items). We then repeated the 
analysis specifying a three-factor model with the MBEP and LF items loading on a single factor. Examination of the chi-square difference test revealed that the four-factor solution was a significantly better fit to the data $\left(\Delta \mathrm{X}^{2}=51.48 ; \Delta \mathrm{df}=3 ; p<.01\right)$. However, the chi-square difference test is sometimes overly sensitive with the sample sizes ( $N>200$ ) typically used in most LISREL analyses (Medsker, Williams, \& Holahan, 1994). Additionally, all three of the computed fit index differences were .01 or less (see Table 1 ), suggesting that the four-factor model is not a meaningfully better fit than is the three-factor model (Medsker et al., 1994).

Further examination of the results shown in Table 1 indicates that the overall fit for both models is not exceptionally high (Hu \& Bentler, 1999). The completely standardized four-factor solution is presented in Table 2, and all of the factor loadings shown are statistically significant $(p<.05)$.

Although the obtained factor-analytic results reveal that all the item loadings are statistically significant, several item loadings are of marginal magnitude. Items LF5, MBEP4, MBEP6, MBEA3, MBEA5, and CRW1 all have error (unexplained) variance in excess of .80, suggesting that these items do not adequately represent their respective latent constructs.

Finally, we conducted a correlation analysis to determine if the data from this sample were consistent with data used in previous research. All of the correlations among the four scales were within the ranges found in prior studies (Tejeda et al., 2001), which provides us with increased confidence about the generalizability of results from this sample. The obtained correlations are presented in Table 3.

\section{Discussion}

The results of these analyses are consistent with those of prior studies that have examined the MLQ transactional and nonleadership measures together. Although the four-factor model provided a better fit to the data, the three-factor model (in which all of the MBEP and LF items had statistically significant loadings on a single factor) was only a slightly poorer fit. A similar result has been found using confirmatory factor analysis in prior studies, where a "passive leadership" factor emerged (Bass et al., 2003).

The correlation between the LF and MBEP measures was also very strong (.78), as has been found previously. We will therefore explore possible conceptual and empirical overlap in these measures in considerably more detail below (stage 4). Both CRW and MBEA demonstrated a stable factor structure in the confirmatory factor analyses, but several items had marginal loadings and high error variance. This suggests that there are also potential problems with these measures that merit attention. Recent research has explored the possibility that the MLQ measure of contingent reward (CRW) may be multidimensional (Goodwin, Wofford, \& Whittington, 2001). We will now examine this issue in more detail, followed by an analysis of the MBEA measure and an assessment of the theoretical content validity of the LF and MBEP items.

\section{Stage 2: Examination of the MLQ contingent reward measure}

Contingent reward is conceptualized by Bass and his associates as involving clarifying goals and objectives and recognizing achievement. The transaction process is seen as the basis for building leaderfollower trust (Avolio, 1999; Bass et al., 2003) and it 


\begin{tabular}{|c|c|c|}
\hline & Three-factor & Four-factor \\
\hline Degrees of freedom & 431 & 428 \\
\hline Chi-square & 1181.01 & 1129.52 \\
\hline RMSEA & .09 & .09 \\
\hline CFI & .91 & .91 \\
\hline RFI & 85 & 86 \\
\hline
\end{tabular}

Note. RMSEA = Root mean square error of approximation; CFI= Comparative fit index; RFI=Relative fit index.

Table 2

4factor GFA completely standardized solution

\begin{tabular}{|c|c|c|c|c|}
\hline & LF & MBEP & MBEA & CRW \\
\hline LF1 & 0.61 & - & - & - \\
\hline LF2 & 0.63 & - & - & - \\
\hline LF3 & 0.56 & - & - & - \\
\hline IF4 & 0.76 & - & - & - \\
\hline LF5 & 0.41 & - & - & - \\
\hline IF6 & 0.75 & - & - & - \\
\hline LF7 & 0.61 & - & - & - \\
\hline LF8 & 0.46 & - & - & - \\
\hline MBE.P1 & - & 0.67 & - & - \\
\hline MBEP2 & - & 0.74 & - & - \\
\hline MBEP3 & - & 0.84 & - & - \\
\hline MBE.P4 & - & 0.39 & - & - \\
\hline MBEP5 & - & 0.91 & - & - \\
\hline MBEP6 & - & 0.36 & - & - \\
\hline MBE.P7 & - & 0.93 & - & - \\
\hline MBEA1 & - & - & 0.52 & - \\
\hline MBE.A2 & - & - & 0.46 & - \\
\hline MBE.A3 & - & - & 0.17 & - \\
\hline MBE.A4 & - & - & 0.80 & - \\
\hline MBE.A5 & - & - & 0.21 & - \\
\hline MBE.A6 & - & - & 0.61 & - \\
\hline MBE.A7 & - & - & 0.67 & - \\
\hline CRW1 & - & - & - & 0.41 \\
\hline CRW2 & - & - & - & 0.68 \\
\hline GRW3 & - & - & - & 0.76 \\
\hline CRW4 & - & - & - & 0.83 \\
\hline CRW5 & - & - & - & 0.59 \\
\hline CRW6 & - & - & - & 0.77 \\
\hline CRW7 & - & - & - & 0.68 \\
\hline CRW8 & - & - & - & 0.54 \\
\hline CRW9 & - & - & - & 0.53 \\
\hline
\end{tabular}

Note. IF = laissez-faire, MBEP = passive management by exception, MBEA = active management b exception, CRW = contingent reward.

has been the most widely studied sub-dimension of the MLQ(Dumdum et al., 2002). Not surprisingly (given Bass and associates' conceptualization), Yukl (1999), in his review of the MLQ, describes the contingent reward measure (CRW) as including items that represent an interpersonal exchange process as well as items that represent praise and recognition. However, Yukl (1999) describes the latter behaviors as being more transformational than transactional. Furthermore, Avolio (1999) suggests that there may be higher- and lower-order transactions constituting contingent reward, the higher-order transactions being more transformational in nature. Other studies have also found the CRW measure to be positively related to the MLQ transformational leadership subscales, both correlationally and factoranalytically (Avolio et al., 1999; Bycio, Hackett, \& Allen, 1995; Tejeda et al., 2001).

A particularly noteworthy study of the MLQ CRW scale was undertaken by Goodwin et al. (2001), who used a sample of 154 government employees to conduct a confirmatory factor analysis of the CRW items alone. Goodwin et al. found that the CRW items did indeed produce two factors. Two of the CRW items, items five and six, did not load very strongly and item 5 was dropped from the analyses. Goodwin 
et al. labeled the two factors "explicit psychological contract" (EPC), comprised of CRW items one through four, and "implicit psychological contract" (IPC), comprised of items six through nine. EPC was so named because the authors believed that this subset of items describes an explicit negotiation of rewards based on performance, while IPC was based on faith that the leader will follow through on rewards promised for good performance. This analysis empirically supported the idea advanced by Yukl (1999) that contingent reward, as operationalized by Bass and associates, involves both an interpersonal

\section{Table 3}

MBEP, MBEA, LF, and CRW scale intercorrelations

\begin{tabular}{|c|c|c|c|c|}
\hline & MBEP & MBEA & LF & CRW \\
\hline$\overline{\text { MBEP }}$ & 86 & & & \\
\hline MBE.A & $22^{k-k}$ & .69 & & \\
\hline IF & $.78^{*-k}$ & $.15^{*}$ & .82 & \\
\hline CRW & $-.28^{k-k}$ & .01 & $-.28^{k-k}$ & 87 \\
\hline
\end{tabular}

Note. MBEP = passive management by exception; MBEA = active management by exception; LF = laissez-faire; CRW = contingent reward. Internal consistency reliabilities shown on the diagonal.

${ }^{* *}$ Correlation is significant at the 0.01 level (2-tailed).

* Correlation is significant at the 0.05 level (2-tailed).

exchange process as well as recognition. Below are the CRW items as classified by Goodwin et al. (2001), showing that the EPC items represent an explicit exchange while the IPC items represent more implicit rewards and recognition:

1. Gives me what I want in exchange for my support. (EPC)

2. Makes clear what I can expect to receive, if my performance meets designated standards. (EPC)

3. Works out agreements with me on what I will receive if I do what needs to be done. (EPC)

4. Negotiates with me about what I can expect to receive for what I accomplish. (EPC)

5. Provides his/her assistance in exchange for my effort. (Omitted item)

6. Tells me what to do to be rewarded for my efforts. (IPC)

7. Makes sure that we receive appropriate rewards for achieving performance targets. (IPC)

8. I earn credit with him/her by doing my job well. (IPC)

9. Expresses his/her satisfaction when I do a good job. (IPC)

In a higher-order CFA, Goodwin et al. hypothesized that the IPC items would load on a single factor with four transformational leadership subscales (ascribed charisma, inspirational leadership, intellectual stimulation, and individualized consideration), while the EPC items were hypothesized to load on a separate factor with two transactional subscales (active and passive management by exception). The IPC items loaded as predicted but the EPC and management by exception items did not load significantly on a single transactional dimension. We do not see this result as surprising, however, as EPC is a subset of CRW and CRW has been shown to have little relationship with the MLQ management by exception scales in prior studies (Bycio et al., 1995; Wofford, Goodwin, \& Whittington, 1998; Yukl, 1999).

Goodwin et al. repeated their analyses with a group of 209 employees from a variety of organizations and once again found a two-factor solution for the contingent reward subscale. They then found that a transformational measure that included the idealized influence, inspirational motivation, intellectual stimulation, and individualized consideration measures and the four IPC items was positively correlated with subordinate organizational citizenship and performance. A transactional measure that 
included the 14 active and passive management by exception items and the four EPC items was negatively correlated with the same measures. Goodwin et al. did not, however, examine the individual effects of the IPC and EPC measures.

Along similar lines, Bass et al. (2003) tested for an "augmentation effect" of transformational leadership on contingent reward. They found that when "lower order" CRW items were included in a hierarchical regression analysis, transformational leadership had a positive effect on perceived performance. It did not have such an effect when the "higher order" CRW items were included in the analysis.

Rafferty \& Griffin (2004) developed measures of transformational leadership using items from House (1996) and Podsakoff, McKenzie, Moorman, \& Fetter (1990). Though comprised of different items, the subscales of vision, inspirational communication, intellectual stimulation, and supportive leadership were similar to the transformational leadership scales of the MLQ. They also selected three Podsakoff et al. (1990) items to form a measure that they termed "personal recognition," which was included as part of their transformational leadership measure. The measure had a small positive correlation with organization commitment and a small negative correlation with turnover intentions. The personal recognition items, however, were originally contingent reward items 3, 4, and 5 from the Leader Reward and Punishment Questionnaire (LRPQ; Podsakoff et al., 1982,1984).

Examining the contingent reward IPC subscale of the MLQ identified by Goodwin et al. (2001) (see the IPC items presented above) shows that it is operationalized very similarly to Rafferty \& Griffin's (2004) "personal recognition" measure that was derived from the contingent reward scale of the LRPQ(it emphasizes the use of implicit rewards and recognition to motivate subordinates):

1. Commends me when I do a better than average job. (LRPQ-CR4)

2. Acknowledges improvement in my quality of work. (LRPQ-CR3)

3. Personally compliments me when I do outstanding work. (LRPQ-CR5)

Bass et al. (2003, p.215) discuss the findings of Goodwin et al. (2001) in some detail and suggest that, "Future research now needs to explore the distinction between higher and lower order forms of contingent reward leadership and their relationship to motivation and performance."

In an effort to better understand the MLQCRW construct we therefore replicated the Goodwin et al. study but then carried it further by directly examining the convergent and discriminant validity of the IPC and EPC using correlations and exploratory factor analysis with the CR and CP items of the LRPQ. As mentioned above, MLQCRW items 5 and 6 did not load favorably in the Goodwin et al. confirmatory factor analysis (CFA), so we wanted to explore the factor loadings and structure in more detail (using exploratory factor analysis; EFA). We then examined relationships with dependent variables. If the EPC and IPC subscales are indeed unique constructs, then it would not be unreasonable to expect them to have at least somewhat different relationships with dependent variables.

\section{Analyses and results}

To examine convergent validity, we first correlated the LRPQCR measure with the MLQCRW measure and with the EPC and IPC subscales. CR and CRW were correlated at .67, while CR correlated more strongly with IPC at .73 than with EPC at .50 (all ps <.01). We then repeated the Goodwin et al. (2001) factor analysis adding the three LRPQCR items used in the Rafferty \& Griffin (2004) study. Again, a clear 2-factor solution emerged with the LRPQ CR items loading with the EPC items. To examine discriminant validity, we conducted a factor analysis of the 9 MLQCRW items. The results were a clear 
two-factor solution that was very similar to the findings of Goodwin et al., with the exception of CRW6, which loaded on the EPC factor as shown in Table 4.

Table 4

CRW factor analysis into IPC and EPC factors

\begin{tabular}{lll}
\hline & IPC & EPC \\
\hline CRW1 (IPC1) & .50 & .18 \\
CRW2 (IPC2) & .56 & .46 \\
CRW3 (IPC3) & .89 & .12 \\
CRW4 (IPC4) & .84 & .26 \\
CRW5 (EPC1) & .42 & .56 \\
CRW6 (EPC2) & .77 & .29 \\
CRW7 (EPC3) & .42 & .68 \\
CRW8 (EPC4) & .20 & .76 \\
CRW9 (EPC5) & .10 & .87 \\
\hline
\end{tabular}

Note. Extraction Method: Principal Component Analysis.

Rotation Method: Varimax with Kaiser Normalization.

Bold denotes the item's highest factor loading.

We next regressed the IPC and EPC measures on our two dependent variables, satisfaction with supervision and supervisor effectiveness. Only IPC was significant with satisfaction, while both EPC and IPC had a significant positive relationship with perceptions of supervisory effectiveness (as shown in Table 5).

Finally, we correlated the EPC and IPC subscales with the other transactional and non-leadership measures (MBEA, MBEP, and LF). The EPC and IPC measures correlated with each other at only .55 ( $p<$ .01), and the pattern of relationships differed. EPC was positively but nonsignificantly correlated with MBEA (.08; ns), while IPC was negatively and significantly correlated (-.13; $p<.05)$. Additionally, while both were negatively and significantly correlated with MBEP and LF, IPC obtained a considerably more negative relationship (-.43 as compared to -.21 ; both $p<.01)$. Table 6 presents these results.

\section{Discussion}

As suggested by Avolio (1999) and Yukl (1999) and found by Goodwin et al. (2001) and the current study, it appears that the MLQ CRW scale is indeed not unidimensional. The fact that the CRW factor usually retains its structural integrity when subjected to confirmatory factor analysis with other measures of the MLQ suggests that the CRW items are more strongly related to each other than to the other MLQ items (even though many studies have shown CRW to be strongly related to the transformational leadership measures; Dumdum et al., 2002). However, with a more focused microscope, the underlying dimensions of CRW can be seen to emerge.

The two CRW sub-dimensions are empirically correlated but theoretically independent-which the series of factor, regression, and correlation analyses presented above suggests. One sub-dimension, labeled $\mathrm{EPQ}$, is transactional in nature, where positive outcomes are offered in exchange for a desired behavior. According to Goodwin et al., "The exchange of rewards for acceptable performance seems to represent the very epitome of transactional, or exchange, behavior" (2001, p. 760). While Goodwin et al. suggest there is a psychological contract involved in this transaction, the EPC items are very similar to the exchange items developed by Kipnis \& Schmidt (1982) in their influence tactics measure, called the Profile of Organizational Influence Strategies (POIS) (cf. Schriesheim \& Hinkin, 1990). For example, one item is "Offered an exchange (e.g., if you do this for me, I will do something for you)." It is not clear that the EPC (explicit psychological contract) label is an appropriate name for this sub- dimension-since "exchange" is both more parsimonious and also less inferential with respect to actual item content. Yukl (2006) presents a scale similar to the exchange dimension of the POIS, called "promised exchange" and 
other, equally descriptive labels might be "exchange negotiation" or "reward clarification."

The second sub-dimension, labeled IPC (implicit psychological contract) by Goodwin et al. (2001), may be more appropriately called true contingent reward behavior, since most of the items involve a positive outcome being given following the display of a desired behavior. Additionally, the high IPC convergence with the LRPQ contingent reward items obtained in the current study provides supportive evidence for relabeling IPC as "contingent reward." Thus, based on the discussion above, we believe that the EPC and IPC labels do not accurately reflect the actual item content of the measures and that they should be called "exchange negotiation" and "contingent reward," respectively .

The studies by Rafferty \& Griffin (2004), Tejeda et al. (2001), and others suggest that contingent reward is a transformational behavior, while exchange negotiation is transactional but largely unrelated to other MLQ transactional leadership measures. The fact that the two sub-dimensions had different relationships with satisfaction with supervision and supervisor effectiveness

\begin{tabular}{|c|c|c|c|c|}
\hline & \multicolumn{4}{|c|}{ Dependent variable } \\
\hline & \multicolumn{2}{|c|}{ SUPSAT } & \multicolumn{2}{|c|}{ SUPEFF } \\
\hline & Beta & $p$ & Beta & $p$ \\
\hline IPC & .64 & .01 & .61 & .01 \\
\hline EPC & .11 & NS & .13 & .05 \\
\hline R2 & .41 & & .47 & \\
\hline
\end{tabular}

Table 6

EPC, IPC, MBEA, MBEP, and LF scale intercorrelations

\begin{tabular}{lllll}
\hline & EPC & IPC & MBEA & MBEP \\
\hline EPC & - & & & \\
IPC & $.55^{* *}$ & - & - & \\
MBEA & .08 & $-.13^{*}$ & $.22^{* *}$ & - \\
MBEP & $-.22^{* *}$ & $-.43^{* *}$ & $.16^{*}$ & $.78^{* *}$ \\
LF & $-.20^{* *}$ & $-.43^{* *}$ & - \\
\hline
\end{tabular}

Note. $\mathrm{EPC}=$ Explicit psychological contract; IPC = Implicit psychological contract; MBEA = Active management by exception; MBEP = Passive management by exception; LF = Laissez-faire.

${ }^{* * *}$ Correlation is significant at the 0.01 level (2-tailed).

*Correlation is significant at the 0.05 level (2-tailed).

reinforces this idea. While contingent reward had a positive relationship with both satisfaction and performance, exchange was related only to performance, similar perhaps to a feeling of equity.

\section{Stage 3: Examination of the MLQ active management by exception measure}

Active management by exception (MBEA) is operationalized on the MLQ as supervisors looking for mistakes and closely monitoring subordinate performance. This is similar in nature to the contingent punishment construct of the LRPQ(Podsakoff et al., 1982,1984). Although Yukl (1999) is critical of the MBEA measure for a number of reasons, it has shown a stable factor structure in the few confirmatory factor analysis studies that have reported results (Avolio et al., 1999; Antonakis et al., 2003).

MBEA's relationship with satisfaction with supervision and perceptions of supervisor effectiveness were reported in a metaanalysis recently conducted by Dumdum et al. (2002). Dumdum and associates found very small negative correlations with satisfaction and small positive correlations with effectiveness. Earlier, Avolio (1999) noted that there are situations when MBEA would be appropriate but that if it were 
used excessively subordinates might perceive it as an ineffective leader behavior. It therefore seems that while MBEA could be an effective behavior in certain situations, its effects on the perceptions of subordinates appears to be, at most, minor.

Although the MBEA items have formed a unique factor using confirmatory factor analysis, there is some suggestive evidence that the scale may lack unidimensionality. In the current study (stage 1; see Table 2), two of the items (MBEA3 and MBEA5) had large amounts of unexplained (error) variance. In a recent study by Bass et al. (2003), the MBEA measure was eliminated from use due to low internal consistency reliability (.56). Similarly, Tejeda et al. (2001) found that MBEA had low internal consistency reliabilities in two separate samples and, as mentioned earlier, it obtained a somewhat low coefficient alpha in the current study (.69).

\section{Analyses and results}

To examine the relationship of the MBEA items to each other, an exploratory factor analysis (EFA) was conducted using just the 7 MBEA items, similar to our analysis of the CRW items described above in stage 2. Once again, the EFA resulted in a two-factor solution that explained $52.13 \%$ of total item variance. MBEA1, MBEA4, MBEA6, and MBEA7 formed one factor, while MBEA2, MBEA3 and MBEA5 loaded together to create a second factor. The factor analysis was next repeated including the MBEA and LRPQCP items. The results this time, however (unlike the CRW examination), had the CP items form a separate factor (and a total of $54.92 \%$ of the item variance was explained). Table 7 presents these results. Here, it can be seen that two MBEA items, MBEA2 and MBEA5, had substantial cross loadings (>.40; cf. Ford, MacCallum, \& Tait, 1986) on the CP factor. Additionally, all of the MBEA items except MBEA3 and MBEA5 had meaningful loadings on Factor 2. MBEA3 and MBEA5 alone defined Factor 3.

\begin{tabular}{|c|c|c|c|}
\hline & $\mathrm{CP}$ & MBEA1 & MBEA2 \\
\hline$\overline{\text { MBEA1 }}$ & .16 & .63 & .19 \\
\hline MBEA2 & .44 & .41 & .24 \\
\hline MBEA3 & -.12 & .08 & .85 \\
\hline MBEA4 & .16 & .81 & .08 \\
\hline MBEA5 & .43 & .10 & .48 \\
\hline MBEA6 & -.04 & .74 & .12 \\
\hline MBEA7 & .11 & .76 & -.19 \\
\hline CP1 & .67 & .21 & -.07 \\
\hline $\mathrm{CP} 2$ & .67 & .07 & .07 \\
\hline $\mathrm{CP} 3$ & .77 & .02 & -.05 \\
\hline CP4 & .75 & .08 & .06 \\
\hline
\end{tabular}

Extraction Method: Principal Component Analysis. Rotation Method: Varimax with Kaiser Normalization. Bold denotes the item's highest factor loading. 


\section{Discussion}

These results, and the modest correlation between the two measures $(r=.29 ; p<.01)$, suggest that $C P$ and MBEA represent different constructs. The factor-analytic results also suggest that items MBEA1, MBEA 4, MBEA6, and MBEA7 might best represent MBEA. These results are very similar to those of Tejeda et al. (2001) who, using item-to-subscale correlations, determined that the MBEA4, MBEA 6 and MBEA 7 items best represented the active management by exception construct (similarly, those three items had the strongest factor loadings in our analysis above).

Looking at the effects of deleting MBEA items 2, 3, and 5 from the MBEA scale produced further findings that support their elimination from the MLQ. The coefficient alpha reliability of the scale improved to .74 (from .69) with the three items deleted. Additionally, the scale's correlation with satisfaction with supervision $(-.31, p<.01)$ and supervisory performance $(r=-.33, p<.01)$ also strengthened (from - .18 and -.17 , respectively; both at $\mathrm{p}<.05$ ). Poor item content might thus be one explanation for the weak MBEA relationships that are typically reported in the literature (Dumdum et al., 2002).

It is not obvious why the MBEA construct appears to be multidimensional. However, the measure was developed inductively, by interpreting descriptions provided by respondents. Without an a priori theoretical definition of the construct under examination it can be very difficult to develop items that will be conceptually consistent (Hinkin, 2005) or unidimensional (Schriesheim, Powers, Scandura, Gardiner, \& Lankau, 1993). In addition, an examination of the wording of the items shows that three of the eight items include the word "my." This could change the point of reference from behaviors generally displayed toward subordinates (e.g., as a group) to how the manager interacts with a specific individual. Once again, while the MBEA items typically load on a single factor using confirmatory or exploratory factor analysis that includes all of the MLQ transactional leadership items, the evidence presented here suggests that this measure is not unidimensional (when examined by itself). Thus, further theoretical and empirical investigation of the active management by exception construct appears highly desirable.

\section{Stage 4: Examination of passive management by exception and laissez-faire leadership}

MBEP and LF have been the least studied dimensions of the MLQ (Dumdum et al., 2002). However, some earlier studies (e.g., Bass et al., 2003), as well as our analyses in stage 1 of this investigation, suggest that conceptual or theoretical overlap between these two sub-dimensions may be problematic. Consequently, this last part of the current research examines them together.

The operational definition of passive management by exception is that supervisors only intervene after noncompliance has occurred or when mistakes have already happened. It is not construed as a form of punishment because most of the items are phrased in a non-personal manner. Laissez-faire is operationalized as managers avoiding making decisions, abdicating responsibility, and not using their authority. It is essentially a non-response to situations that may merit attention.

Although conceptualized as quite different constructs by Bass and his associates, empirically there has been substantial overlap between the MBEP and LF measures. Two explanations seem most plausible for this situation. First, managers who tend to use MBEP also tend to use LF. Second, respondents have a difficult time perceptually distinguishing between the two measures since their items tap the same general domain (passive leadership).

Several studies have subjected these scales to confirmatory factor analysis and found that their items tended to load on a single factor, which has been called "passive/corrective leadership" (Avolio et al., 1999; Den Hartog et al., 1997). There is also evidence that the use of these types of leader behaviors 
could have negative consequences for organizations. A recent meta-analysis found that MBEP and LF had moderately strong negative relationships with effectiveness and satisfaction, - .46 and - .38 for MBEP and - .37 and - .53 for LF, respectively (Dumdum et al., 2002). However, even though a number of studies have shown both of these behaviors to have strong negative correlations with satisfaction and effectiveness, little attention has been paid to the impact that passive leadership can have on organizations. Avolio (1999, p. 55) describes these types of behaviors as "highly dissatisfying." Bass et al. (2003) found that being a passive leader was counterproductive. These findings, along with the results of the factor analyses presented above, suggest that the two constructs should be further examined. The current study focused on an examination of the content validity or adequacy of the passive management by exception and laissez-faire leadership measures.

\section{Sample and procedure}

\section{Sample}

For this stage it was necessary to collect data from another sample in order to conduct the analyses described below. This sample was comprised of $62 \mathrm{MBA}$ students at a private southern university enrolled in a leadership course (at the beginning of the class, before any leadership theories were discussed). The sample consisted of $69 \%$ males and the average age was 29 . As noted in Schriesheim and associates (Schriesheim, Cogliser, Scandura, Lankau, \& Powers, 1999; Schriesheim et al., 1993), the requirements to satisfactorily complete the task that we assigned the respondents are sufficient intellectual ability to read and rate questionnaire items and the lack of any clear or consistent theoretical biases. As such, the use of MBA students seemed appropriate. Explicit written and verbal instructions were provided prior to our administration of the rating instrument, and responses were anonymous. Rating questionnaires were distributed in class and collected the following class period; the students received extra credit for completing the survey.

\section{Procedure}

In an attempt to isolate those items that best represent the MBEP and LF constructs, a content validity or content adequacy assessment (Schriesheim et al., 1993,1999) was conducted using the ANOVA analytic procedure developed by Hinkin \& Tracey (1999). This approach can be used for testing existing measures or new measures, while the ANOVA technique eliminates the use of subjective judgment for determining item adequacy (ANOVA provides a direct empirical test for determining item distinctiveness). Additionally, ANOVA is very simple and straightforward. Finally, this technique can be utilized with small sample sizes, which is desirable for addressing both practical and statistical differences (cf. Cohen, 1969).

To conduct the analysis, items from similar yet different construct measures are presented to respondents along with definitions of each of the constructs. In this case, the MBEP and LF items were used, in addition to scales measuring non-response to good performance (NG) and non-response to poor performance (NP) developed by Hinkin \& Schriesheim (2005). MBEP is characterized by a leader taking no action until things go very wrong (Yukl, 1999). For example, MBEP3 is "My manager fails to intervene until problems become serious." When the response does come, it may be perceived as unrelated to prior behavior, as time may pass between when the problem arose and the manager's action. From a reinforcement perspective, the subordinate may wonder why the manager did not correct inappropriate behavior when it was first observed. Similarly, laissez-faire leadership is characterized by ignoring problems and subordinate needs, in essence showing indifference about the task and subordinates (Yukl, 2006). Item LF2 is "My manager takes no action even when problems become chronic." Regardless of 
subordinate performance, the laissez-faire leader would most likely be non-responsive.

The two non-response (NP, NG) measures were based on classic reinforcement theory, where extinction is a very important behavioral consequence in traditional operant conditioning research (Rachlin, 1989; Skinner, 1969). Reinforcement theory would predict that not responding to a behavior over time would eventually extinguish that behavior (however, some argue that extinction of an undesired behavior works best in conjunction with use of positive reinforcement of desired behavior; cf. Luthans \& Kreitner, 1985). The MBEP and LF sub-dimensions of the MLQare the measures currently in use in leadership research that appear most similar to the concept of extinction, since both involve a lack of response to subordinate behavior (whether that behavior be desirable or undesirable).

The non-response to good performance (NG) measure is made up of two LRPQ contingent reward items (reverse-scored CR items 09 and 10: "My good performance often goes unacknowledged by my supervisor," and "I often perform well in my job and still receive no praise from my supervisor") and four items developed based on the definition presented in Appendix A. Six nonresponse to poor performance (NP) items were likewise developed, also based on the construct definition in Appendix A. For example, NP6 is "My poor performance often gets no response from my manager." (For more detail on the development of the NG and NP measures and their psychometric properties, see Hinkin \& Schriesheim, 2005).

\section{Analyses and results}

Each respondent was given a four-page rating questionnaire that contained definitions of the constructs to be assessed. Extreme care was taken to ensure that the MBEP and LF definitions were consistent with Bass \& Avolio's (1994) conceptualization. The definition of one of the four leader behaviors was presented at the top of each page of the questionnaire, followed by a randomized listing of all the items. The respondents rated each of 27 leader behavior items ( 8 LF, 7 MBEP, 6 NG, and 6 NP) on the extent to which they believed the items were consistent with each of the four leader behavior definitions. See Appendix A for the definitions and items. Two versions of the questionnaire were administered, each with the pages presented in a different order, to control for response bias that may occur from order effects. No statistically significant differences among responses across the versions were found.

Of the 15 MLQ items, LF2, MBEP4, and MBEP6 were classified as measuring a construct other than the MLQdimension to which they are currently assigned. All of the others, as well as the 12 nonresponse (NG and NP) items, were classified appropriately.

Looking at individual MLQ items, LF2 ("My manager takes no action even when problems become chronic") was classified as non-response to poor performance (NP). MBEP4 ("My manager tells me what I've done wrong rather than what I've done right") was classified as non-response to good performance (NG). It is also the only MBEP item that contains the word "me," which may alter the referent for the respondent (see the earlier discussion in stage 3 of this potential effect with respect to the word "my").

MBEP6 ("My manager shows he/she is a firm believer in 'If it ain't broke, don't fix it'") was classified as an LF item. Interestingly, the two misclassified MBEP items had low factor loadings and subsequent high error variance in the confirmatory factor analysis conducted with the first sample in stage 1 of this research. In fact, all three of the MLQmisclassifications appear reasonable to us, as the items seem to be more consistent with the definitions of the dimensions to which they were actually assigned than with the definitions of the MLQ dimensions in whose subscales they currently appear (see Appendix $A$ for the rating definitions that were employed). 


\section{Discussion}

Twelve of the fifteen MLQ items that were examined were classified correctly in the content adequacy examination. However, three MLQ items were misclassified. It therefore seems reasonable to suggest that the MBEP scale be modified by eliminating items MBEP4 and MBEP6, so as to remove undesirable representation of non-response and laissez-faire leadership, respectively. Similarly, item LF2 of the laissez-faire leadership scale appears to theoretically represent non-response and should, therefore, also be eliminated. Eliminating these three items should improve the validity of the LF and MBEP scales. However, these two scales still remain problematic due to their items loading on the same factor in some analyses and their consistently high intercorrelation.

\section{General discussion}

Over the past several decades there have been many pleas about the importance of appropriate scale development procedures in conducting survey research (e.g., Guion, 1977; Ford et al., 1986; Hinkin, 1995; Schriesheim et al., 1993). Despite this, there continue to be measures that are developed and put into use without adequate theory and demonstration of construct validity (Scandura \& Williams, 2000). In the case of the MLQ the items were derived inductively and aggregated into measures using empirical data reduction methods. Simply because items load on the same factor does not guarantee that they represent the same theoretical content domain (Nunnally \& Bernstein, 1994; Schriesheim et al., 1993,1999). Many researchers have questioned the content validity of the MLQ over the years, and the developers have made frequent attempts to modify the measure to overcome various criticisms. Consequently, the MLQ has evolved and improved over the years. Recognizing this, we offer several suggestions that we believe are constructive and also desirable for both future revision of the MLQ and for future research that uses it to study transactional leadership phenomena. First we will present a brief summary of our findings that relates to our research questions:

To begin with, we believe that theory is seriously underdeveloped in this domain, particularly with respect to the MLQ transactional and non-leadership dimensions. It is true that theoretical definitions have been provided for each of the four MLQ non-transformational leadership scales. However, there is little theoretical justification provided for why these four dimensions (CRW, MBEA, MBEP, and LF) are (or should be) considered of particular theoretical interest and importance for advancing knowledge about transactional leadership phenomena.

The contingent reward dimension has received serious theoretical treatment by Podsakoff and his associates (e.g., Podsakoff et al., 1982,1984) and others, so that less theoretical work is needed with respect to this dimension. However, our research, as well as the Goodwin et al. (2001) study, clearly shows that the MLQ contingent reward measure (CRW) is multidimensional. We have demonstrated that, not only do the items load on two factors, but also the sub-dimensions have different relationships with both dependent variables and other transactional leadership measures. Based on these results and our discriminant validity assessment, we would therefore recommend that CRW items 1-4 best represent the $M L Q$ contingent reward dimension. These items also appear to constitute the "higher order" contingent reward measure proposed by Avolio (1999) and Bass et al. (2003). Most likely, then, they also could be considered to measure a type of transformational rather than transactional leader behavior in future research. However, additional theory elaborating why transformational effects should be produced by "higher order" contingent reward behavior is clearly needed.

Even though the CRW exchange items have been shown to load on the same factor as the 
contingent reward items when all the MLQ transactional items are included in a factor analysis, they appear to theoretically represent exchange, a transactional leader behavior. Our within-measure factor analysis clearly demonstrated that they are perceived as measuring a separate construct. This suggests the possibility of using these items as the basis for developing a new transactional exchange scale, perhaps by adding additional appropriate items taken or modified from the POIS (Kipnis \& Schmidt, 1982) or the LRPQ(Podsakoff et al., 1982,1984). Adding additional items to the "higher order" contingent reward scale discussed above may also be desirable to ensure adequate internal consistency reliability in future research.

Looking closely at MBEA, the implications of our findings seem more complex. The internal consistency reliability of the MBEA measure was low at .69, a problem identified in prior studies (Bass et al., 2003; Tejeda et al., 2001). The results of our factor analysis, revised reliability analysis, and correlational analysis would seem to suggest retaining items $1,4,6$, and 7-virtually the same results found by Tejeda et al. (2001) (who used confirmatory factor analysis to reduce the number of items that they used in an improved MBEA measure). A closer inspection of these four items, however, shows that two have the referent "my" (MBEA4 and MBEA7) while two items (MBEA1 and MBEA6) are more general. Empirically, this is may not be a concern, as it appears that our respondents did not differentiate between the two perspectives in our exploratory factor analysis. However, conceptually they may be very different and this difference may even affect the appropriate level of analysis at which the items should be employed (e.g., individual or group/unit; cf. Yammarino \& Dubinsky, 1992). Rewording of these MBEA items so that all four are consistent with respect to referent thus may be desirable. Also desirable might be the inclusion of additional items to enhance scale internal consistency reliability.

Additionally, we should perhaps mention that the one MBEP item with the word "me" in it was problematic in both the content adequacy and factor analyses presented above. Item wording differences can be subtle but important, as they may affect responses to a question (Hinkin, 1998). We would therefore recommend that before any MBEA items are reworded that appropriate theory be further developed and that a content adequacy assessment be used (similar to what we used for the LF and MBEP items) to identify the approach that best represents the MBEA theoretical construct (e.g., individual or group/unit). We did not do this for the current study as we did not anticipate this problem with the MBEA measure. Also, such an undertaking requires the development of additional clarifying theory (which would add considerable additional length to this manuscript) and it is probably something that the MLQ developers would prefer to do themselves. However, additional theorization is clearly needed. For example, "Why does (or should) MBEA matter?" "Why is MBEA important enough to warrant research focus over other types of non-transformational leader behaviors (such as paying adequate attention to routine administrative duties)?" (cf. Miner, 1975).

The same theoretical concerns also exist with respect to the MBEP and LF dimensions. To date, passive or non-leadership (MBEP and LF) have received very little examination or theoretical development. However, both have demonstrated reasonably consistent negative relationships with important dependent variables that are as large in magnitude as the much more studied transformational leadership measures. Thus, it may be just as important to study what managers don't do as it is to study what they do. Questions such as "What are the effects of non-responsive leader behavior over time?" and "How does non-responsive leader behavior affect high performing subordinates?" clearly need future investigation.

Another question that may be asked is whether leaders who show passive management by exception also simultaneously use laissez-faire leadership_or whether subordinates perceptually 
confuse these two constructs when describing their leader's behavior. However, while our respondents in the content adequacy assessment (the stage 4 study) were able to differentiate between the two constructs, the measures are very highly correlated, load on a single factor, and have virtually the same relationships with other variables. This suggests that they both may reflect a more general "passive" leadership style characterized by managers who tend to avoid interacting with their subordinates unless it is absolutely necessary. This idea is consistent with previous studies (e.g., Bass et al., 2003; Den Hartog et al., 1997). We would therefore suggest that, from a research perspective, the two dimensions can be theoretically differentiated but that they are also operationally redundant. Researchers might be best advised to use a revised LF measure (deleting item LF2) to capture passive or non-leadership, as it has demonstrated stronger psychometric properties in this and previous studies. However, a revised MBEP measure (deleting items MBEP4 and MBEP6) could also be employed as an alternative. Using both measures together would increase questionnaire length and seem to provide little benefit for researchers. However, more theory is clearly needed here, differentiating MBEP from LF, particularly with respect to antecedents and consequences.

\section{Study limitations}

One issue regarding this study that warrants some discussion is the extent to which common method variance should be viewed as problematic and an alternate explanation for some or all of our obtained findings (cf. Podsakoff, MacKenzie, Lee, \& Podsakoff, 2003).

In designing our study, we did not attempt to directly deal with common method variance (Podsakoff et al., 2003). This is because we did not include a marker variable in our research instruments (there was none that we could identify a priori as being clearly "theoretically appropriate"). Also, there are serious concerns about the appropriateness of the post hoc procedures that have been developed to address common method variance concerns (Richardson, Simmering, \& Sturman, 2006). ${ }^{1}$ Finally, we believed that we had four additional reasons to be less worried about common method variance effects.

First, some of our work partially replicated the earlier research of others. This is particularly true with respect to our examination of whether passive management by exception and laissez-faire leadership lack empirical discriminant validity (e.g., Bass et al., 2003) and for our investigation of the dimensionality of the MLQ contingent reward dimension (Goodwin et al., 2001). None of these earlier studies tried to estimate or control common method variance effects, and we wanted to compare our results with the earlier findings - and not lengthen this study further or become entangled in controversy about common method variance effects. We did examine and compare the pattern of our obtained relationships and findings to those typically reported in previous empirical research (see the discussions of this above), and there were no notable differences. This suggests an absence of common method variance problems unique to our investigation.

Second, we used a number of procedural study design remedies that should have reduced the susceptibility of our data to common method bias (Podsakoff et al., 2003). For example, we provided the study participants with very strong verbal and written assurances of respondent anonymity and we also used different questionnaire sections, with different instructions and response scales for each of the measures that we employed.

Third, our confirmatory and exploratory factor analyses were generally aimed at uncovering finer

\footnotetext{
${ }^{1}$ Briefly, we did not use the latent method factor approach recommended by Podsakoff et al. (2003, Fig. 1, Situation 7) because Richardson et al. (2006, p. 34) specifically state that "...we do not recommend using it [the latent method factor approach] as a post hoc technique for controlling for common method variance under any circumstances."
} 
perceptual distinctions among items that had grouped together in courser or more encompassing factor analyses (i.e., factor analyses with items from multiple MLQ scales). The presence of common method variance would be expected to make any obtained results more conservative by masking finer differences among items (Podsakoff \& Organ, 1986). However, we consistently found relatively fine distinctions in the analyses that are reported above.

Last, one of our analyses (the theoretical content assessment of the MBEP and LF scale items) involved a second sample and collected ratings of theoretical content adequacy for which there is absolutely no reason to expect common method bias to have produced our findings. In this sample we presented the items in different order to two subgroups of respondents. Additionally, common method bias would be expected to mask distinctions in item content and yield conservative results with diminished rating differences among the items. This did not appear to happen. Thus, while it may be true that common method variance is often problematic and (Podsakoff et al., 2003), it does not seem reasonable to believe that common method bias is a major limitation of this particular study (cf. Spector, 2006).

Some of the unique aspects of our organizational sample could raise concerns about the generalizability of the results we obtained. For one, our sample size was large enough to use confirmatory factor analysis ( $N>200)$ but still not particularly large. However, we see no reason why the results we obtained would be in question due to sample size alone. The organizational sample included 42 managers as referents, with over 5 respondents per manager. In many ways this appeared to us to be a robust sample, especially given the diversity of organizational units and geographic locations. A number of previous MLQ studies have used smaller samples from a single company or single geographic location, which we would expect would make such results more vulnerable than ours to sample and/or context effects. Additionally, larger samples may provide more statistical power but also may result in statistically significant findings that are of little practical consequence. In summary, all studies can benefit from replication using different samples and methods, and this research is no exception. However, on an overall basis, the consistency of our results with previous studies (particularly with respect to the magnitude of intercorrelations, correlations with dependent variables, and the factor structure of the contingent reward sub-dimensions) offers reassuring evidence that there is probably nothing uniquely idiosyncratic about the organizational sample employed in this investigation or in the results we obtained.

\section{Conclusion}

While there have been problems identified with the MLQ it is very likely that it will continue to be heavily used for the foreseeable future. Several transactional measures have demonstrated strong relationships with important outcome variables (Dumdum et al., 2002) and they are therefore almost certain to be employed in future research. Our research has attempted to identify ways in which the MLQ can be used more effectively to generate reliable and valid results. We believe that the following implications flow naturally from our research: (1) The contingent reward and exchange items of the MLQ contingent reward subscale (identified above) should be used as separate and independent measures. (2) Active management by exception is best represented by a four-item subset of MLQ items; however, such a measure may still have serious concerns. (3) Passive management by exception and laissez-faire leadership can each be best represented theoretically by eliminating some scale items (as previously described). (4) Even though passive management by exception and laissez-faire leadership are theoretically separate and independent, respondents typically do not differentiate between the two when describing their leaders. As such, parsimony suggests that it may be appropriate to use one or the 
other subscale (but not both) to represent "leader non-behavior" in future empirical research.

In conclusion, we have examined only the transactional leadership and non-leadership measures of the MLQ. However, similar analyses would be helpful for the transformational leadership measures, which have also been subject to questioning and criticism (e.g., Yukl, 1999; Tracey \& Hinkin, 1998). Clearly, measurement is at the core of our research endeavors and we should do all we can to help the developers of the MLQ in further refining and validating this important instrument.

\section{Appendix A. Content adequacy definitions and items}

Non-response to good performance (NG). Managers do not respond to what a subordinate perceives to be his/her good performance

Non-response to poor performance (NP). Managers do not respond to what a subordinate perceives to be his/her poor performance.

Passive management by exception (MBEP). Managers only intervene after noncompliance has occurred or when mistakes have already happened.

Laissez-faire leadership (LF). Managers avoid making decisions, abdicate responsibility, and do not use their authority.

1. It requires a failure to meet an objective for my manager to take action. (MBEP1, MLQ4)

2. Manager avoids getting involved when important issues arise. (LF1, MLQ2)

3. My poor performance often gets no response from my manager. (NP6)

4. My manager takes no action even when problems become chronic. (LF2, MLQ10)

5. I often perform well in my job and still receive no praise from my manager. (NG1)

6. Work has to fall below minimum standards for my manager to try to make improvements. (MBEP2, MLQ12)

7. When I perform well my manager usually does nothing. (NG3)

8. My manager is absent when needed. (LF3, MLQ18)

9. My manager gives me no feedback when I perform poorly. (NP2)

10. My manager fails to intervene until problems become serious. (MBEP3, MLQ20)

11. When I perform poorly in my job I receive no criticism from my manager. (NP4)

12. My manager fails to follow up requests for assistance. (LF4, MLQ26)

13. My manager tells me what I've done wrong rather than what I've done right. (MBEP4, MLQ28)

14. My manager often gives me no feedback when I perform well. (NG2)

15. My manager resists expressing his/her views on important issues. (LF5, MLQ34)

16. I seldom get criticized by my manager when I perform poorly. (NP1)

17. Things have to go wrong for my manager to take action. (MBEP5, MLQ36)

18. My good performance often goes unacknowledged by my manager. (NG4)

19. My manager avoids making decisions. (LF6, MLQ42) 
20. My poor performance often goes unacknowledged by my manager. (EP3)

21. My manager shows he/she is a firm believer in "If it ain't broke, don't fix it." (MBEP6, MLQ44)

22. When I perform poorly my manager does nothing. (NP5)

23. My manager delays responding to urgent questions. (LF7, MLQ50)

24. I don't often get praised by my manager when I perform well. (NG5)

25. Problems must become chronic before he/she will take action. (MBEP7, MLQ52)

26. My good performance often gets no response from my manager. (NG6)

27. My manager diverts his/her attention away from addressing work-related problems. (LF8, MLQ58)

\section{References}

Antonakis, J., Avolio, B. J., \& Sivasubramaniam, N. (2003). Context and leadership: An examination of the nine-factor full-range leadership theory using the Multifactor Leadership Questionnaire. Leadership Quarterly, 14, 261-295.

Avolio, B. J. (1999). Full leadership development: Building the vital forces in organizations. Thousand Oaks, CA: Sage Publications.

Avolio, B. J., Bass, B. M., \& Jung, D. I. (1999). Re-examining the components of transformational and transactional leadership using the Multifactor Leadership Questionnaire. Journal of Occupational and Organizational Psychology, 72,441-462.

Bass, B. M. (1985). Leadership and performance beyond expectations. New York: Free Press.

Bass, B. M. (1990). From transactional to transformational leadership: Learning to share the vision. Organizational Dynamics, 18,19-31.

Bass, B. M., \& Avolio, B. J. (1990). Multifactor leadership questionnaire. Palo Alto:

Consulting Psychologists Press.

Bass, B. M., \& Avolio, B. J. (1993). Multifactor leadership questionnaire. Palo Alto, CA:

Consulting Psychologists Press.

Bass, B. M., \& Avolio, B. J. (1994). Improving organizational effectiveness through transformational leadership. Thousand Oaks,CA: Sage.

Bass, B. M., $\quad$ Avolio, B. J., Jung, D. I., \& Berson, Y. (2003). Predicting unit performance by assessing transformational and transactional

leadership. Journal ofApplied

Psychology, 88, 207-218.

Burns, J. M. (1978). Leadership. New York: Harper and Row.

Bycio, P., Hackett, R. D., \& Allen, J. S. (1995). Further assessments of Bass's (1985) conceptualization of transactional and transformational leadership. Journal of Applied Psychology, 80, 468-478.

Cohen, J. (1969). Statistical power analysis for the behavioral sciences. San Diego, CA: Academic Press.

Den Hartog, D. N., Van Muijen, J. J., \& Koopman, P. L. (1997). Transactional versus transformational leadership: An analysis of the MLQ. Journal ofOccupational and Organizational Psychology, 70,19-34. 
Dumdum, U. R., Lowe, K. B., \& Avolio, B. J. (2002). A meta analysis of transformational and transactional leadership. In B. J. Avolio \& F. J. Yammarino (Eds.), Transformational and charismatic leadership: The road ahead (pp. 35-66). Oxford, UK: Elsevier Science.

Ford, J. K., MacCallum, R C., \& Tait, M. (1986). The application of exploratory factor analysis in applied psychology: A critical review and analysis. Personnel Psychology, 39, 291-314.

Goodwin, V. L., Wofford, J. C., \& Whittington, J. L. (2001). A theoretical and empirical extension to the transformational leadership construct. Journal of Organizational Behavior, 22, 759-775.

Guion, R. M. (1977). Content validity: The source of my discontent. Applied Psychological Measurement, 1,10-11.

Hinkin, T. R. (1995). A review of scale development practices in the study of organizations. Journal of Management, 21, 967-988.

Hinkin, T. R. (1998). A brief tutorial on the development of measures for use in survey questionnaires. Organizational Research Methods, 1,104-121.

Hinkin, T. R. (2005). Scale development principles and practices. In R. A. Swanson \& E. F. Holton (Eds.), Research in organizations: Foundational principles, processes, and methods of inquiry. New York: BerrettKoehler Press, pp. 161-180.

Hinkin, T. R., \& Schriesheim (2005). Doing nothing as a managerial behavior: Development and preliminary validation of leader omission and extinction scales. Paper presented at the annual meeting of the Academy of Management, Aug. 8-12, Honolulu.

Hinkin, T. R., \& Tracey, J. B. (1999). An analysis of variance approach to content validation. Organizational Research Methods, 2,175-186.

House, R. J. (1996). Path-goal theory of leadership: Lessons, legacy, and a reformulated theory. The Leadership Quarterly, 7, 323-353.

Hu, L., \& Bentler, P. M. (1999). Cutoff criteria in fix indexes in covariance structure analysis: Conventional criteria versus new alternatives. Structural Equation Modeling, 6,1-55.

Joreskog, K. G., \& Sorbom, D. (2002). LISREL 8.53. Mooresville, IN: Scientific Software, Inc.

Kipnis, D., \& Schmidt, S. M. (1982). Profile of organizational influence strategies. San Diego, CA: University Associates.

Luthans, F., \& Kreitner, R. (1985). Organizational behavior modification and beyond. Glenview, IL: Scott, Foresman.

Medsker, G. J., Williams, L. J., \& Holahan, P. J. (1994). A review of current practices for evaluating causal models in organizational behavior and human resources management research. Journal of Management, 20,439-464.

Miner, J. B. (1975). Challenge of managing. Philadelphia: W. B. Saunders.

Nunnally, J., \& Bernstein, I. (1994). Psychometric theory (3rd ed.). New York: McGraw-Hill.

Podsakoff, P. M., MacKenzie, S. B., Lee, J. Y., \& Podsakoff, N. P. (2003). Common method biases in behavioral research: A critical review of the literature and recommended remedies. Journal of Applied Psychology, 88, 879-903. 
Podsakoff, P. M., MacKenzie, S. B., Moorman, R. H., \& Fetter, R. (1990). Transformational leader behaviors and their effects on followers; trust in leader, satisfaction, and organizational citizenship behaviors. The Leadership Quarterly, 1,107-142.

Podsakoff, P. M., \& Organ, D. W. (1986). Self-reports in organizational research: Problems and prospects. Journal of Management, 12, 31-41.

Podsakoff, P. M., Todor, W. D., Grover, R. A., \& Huber, V. L. (1984). Situational moderators of leader reward and punishment behaviors: Fact or fiction? Organizational Behavior and Human Performance, 34, 21-63.

Podsakoff, P. M., Todor, W. D., \& Skov, R. B. (1982). Effects of leader contingent and noncontingent reward and punishment behaviors on subordinate performance and satisfaction. Academy of Management Journal, 25, 810-821.

Rachlin, H. (1989). Judgment, decision, and choice: A cognitive/behavioral synthesis. New York: W. H. Freeman.

Rafferty, A. E., \& Griffin, M. A. (2004). Dimensions of transformational leadership: Conceptual and empirical extensions. The Leadership Quarterly, 15, 329-354.

Richardson, H. A., Simmering, M. J., \& Sturman, M. C. (2006). Correcting common method variance in self-reported data: An investigation in the context of leadership research. Unpublished manuscript, Louisiana State University, Baton Rouge, LA.

Scandura, T. A., \& Williams, E. A. (2000). Research methodology in management: Current practices, trends, and implications for future research. Academy of Management Journal, 43,1248-1264.

Schriesheim, C. A., Cogliser, C. C., Scandura, T. A., Lankau, M. J., \& Powers, K. J. (1999). An empirical comparison of approaches for quantitatively assessing the content adequacy of paper-and-pencil measurement instruments. Organizational Research Methods, 2,140-156.

Schriesheim, C. A., \& Hinkin, T. R. (1990). Influence tactics used by subordinates: A theoretical and empirical analysis and refinement of the Kipnis, Schmidt, and Wilkinson subscales. Journal of Applied Psychology, 75, 246-257.

Schriesheim, C. A., Powers, K. J., Scandura, T. A., Gardiner, C. C., \& Lankau, M. J. (1993). Improving construct measurement in management research: Comments and a quantitative approach for assessing the theoretical adequacy of paper-and-pencil survey-type instruments. Journal of Management, 19, 385417.

Seltzer, J., \& Bass, B. M. (1990). Transformational leadership: Beyond initiation and structure. Journal ofManagement, 16, 693-704.

Skinner, B. F. (1969). Contingencies ofreinforcement: A theoretical analysis. New York: Appleton-CenturyCrofts.

Spector, P. E. (2006). Method variance in organizational research: Truth or urban legend? Organizational Research Methods, 9, 221-232.

Tejeda, M. J., Scandura, T. A., \& Pillai, R. (2001). The MLQ revisited: Psychometric properties and recommendations. The Leadership Quarterly, 12, 31-52.

Tepper, B. T., \& Percy, P. M. (1994). Structural validity of the Multifactor Leadership Questionnaire. 
Tracey, J. B., \& Hinkin, T. R. (1998). Transformational leadership, or effective management practices? Group and Organization Management, 220-236.

Weiss, D. J., Dawis, R. V., Lofquist, L. H., \& England, G. W. (1967). Manual for the Minnesota satisfaction questionnaire (Minnesota Studies in Vocational Rehabilitation 22). Minneapolis: Industrial Relations Center, University of Minnesota.

Wofford, J. C., Goodwin, V. L., \& Whittington, J. L. (1998). A field study of a cognitive approach to understanding transformational and transactional leadership. The Leadership Quarterly, 9,55-84.

Yammarino, F. J., \& Dubinsky, A. J. (1992). Superior-subordinate relationships: A multiple levels of analysis approach. Human Relations, 45, 575-600.

Yukl, G. A. (1999). An evaluation of conceptual weaknesses in transformational and charismatic leadership theories. The Leadership Quarterly, 10, 285-305.

Yukl, G. A. (2006). Leadership in organizations, (6th ed.) Upper Saddle River, N. J.: Prentice Hall. 